\title{
A atividade lúdica, a criança de 6 anos e o ensino fundamental
}

\author{
Maria Silvia Pinto de Moura Librandi da Rocha
}

\section{Resumo}

O trabalho aqui apresentado refere-se a uma pesquisa realizada em 2006, com objetivo de compreender os impactos da implementação do Ensino Fundamental de 9 anos em 8 turmas de primeiro ano de escolas da rede municipal de uma cidade no interior de São Paulo. Foram objeto de análise as práticas educacionais mais típicas encetadas nestes espaços educacionais, com especial destaque às condições oferecidas para a atividade lúdica. A metodologia usada foi: observação participante, entrevista (com professoras, mães/pais/responsáveis e alunos de 6 anos) e questionário (para orientadoras pedagógicas das pré-escolas frequentadas pelas crianças em 2005). O material empírico permitiu identificar grandes dificuldades para inserção da atividade lúdica nos contextos escolares. Estes resultados permitem indagar: (i) se as escolas terão condições de incluir as brincadeiras como parte do currículo (como prescrevem os documentos oficiais) e (ii) quais as repercussões desta nova forma de escolarização sobre o desenvolvimento psicológico das crianças brasileiras.

Palavras-chave: Ensino Fundamental, recreação, psicogênese.

\section{Game and entertainment for 6 year-old children and elementary school}

\begin{abstract}
This work is the result of a research project developed in 2006. The goal of our study was to understand the impacts of implementing Elementary School with 9 (nine) years length in 8 groups of the first year within public schools in a town of São Paulo State. The focus was to analyze the most typical educational practices found in these schools, with special attention to the offered opportunities to practice games and entertaining activities for learning. The methodology used was: attending observation, interviews (with teachers, mothers, fathers, tutors and 6 (six) years old students) and a questionnaire (for pedagogic counselors of the pre-schooling attended by these children in 2005). The empiric material allowed the researchers to identify great difficulties to include games and entertaining activities in the school context. These results raised the questions (i) whether the schools will have conditions to include games and entertaining activities as part of the curricula(to comply with official documentation) and (ii) what would be the consequences of this new form of teaching regarding psychological development of Brazilian children.
\end{abstract}

Keywords: Fundamental Education, recreation, psychogenesis.

\section{La actividad lúdica, el niño de 6 años y la enseñanza primaria}

\begin{abstract}
Resumen
El trabajo aquí presentado se refiere a una investigación realizada en 2006, con el objetivo de comprender los impactos de la implementación de la enseñanza primaria de nueve años en ocho grupos de primer grado de escuelas de la red municipal de una ciudad en el interior de São Paulo. Fueron objeto de análisis las prácticas educacionales más típicas iniciadas en estos espacios educativos, con especial énfasis en las condiciones ofrecidas para la actividad lúdica. La metodología usada fue: observación participativa, entrevista (con profesoras, madres/padres/ responsables de alumnos de 6 años) y cuestionario (para orientadoras pedagógicas de jardines de infancia frecuentadas por los niños en 2005). El material empírico permitió identificar grandes dificultades para la inserción de actividad lúdica en los contextos escolares. Estos resultados permiten indagar (i) si las escuelas tendrán condiciones de incluir los juegos como parte de la currícula (como disponen los documentos oficiales) y (ii) cuáles serán las repercusiones de esta nueva forma de escolaridad sobre el desarrollo psicológico de los niños brasileños.
\end{abstract}

Palabras-clave: Educacion primaria, recreacion, psicogenesis. 


\section{Introdução}

O ano de 2006 representa, seguramente, um marco na história das políticas públicas em relação à infância das crianças brasileiras e às suas experiências de escolarização. Trata-se do momento em que se oficializou uma mudança de grande importância para o sistema escolar: a implantação do Ensino Fundamental de 9 anos.

A definição deste novo sistema concretizou-se através da publicação de duas leis: a Lei n 11.114 e a Lei 11.274 , em 2005 e 2006, respectivamente. A primeira delas (Lei $n^{\circ} 11.114$ ) criou, em 16 de maio de 2005, a obrigatoriedade de matrícula de meninos e meninas de seis anos de idade no primeiro ano do Ensino Fundamental. Entretanto, este documento estabelecia que a duração deste segmento deveria ser de, no mínimo, oito anos. Ou seja, a criança poderia entrar aos seis anos e sair aos 13, o que se entendeu que acarretaria problemas pedagógicos. Para corrigir esse problema - e com a finalidade de cumprir as metas estipuladas pelo Plano Nacional de Educação (PNE) -, o Ministério da Educação enviou ao Congresso Nacional o Projeto de Lei 5.452/2005, que tramitou sob regime de urgência. Deste projeto, resultou a Lei 11.274, promulgada em 06 de fevereiro de 2006. Estava, assim, oficialmente, definido o novo modo de funcionamento do ensino obrigatório para as crianças brasileiras: seu ingresso na escola, a partir de então, deverá ocorrer aos seis anos de idade e a sua duração será de - no mínimo - 9 anos.

A análise de documentos oficiais (Ministério da Educação e do Desporto [MEC], 2004a, 2004b, 2006a, 2006b; Lei $n^{\circ} 11.114 / 2005$ e Lei $\left.n^{\circ} 11.274 / 2006\right)$ que apresentam esta nova forma de conceber o Ensino Fundamental permite identificar que se pretende atingir os seguintes objetivos, com as decisões tomadas:

1. aumentar o número de crianças incluídas no sistema educacional, oportunizando o acesso à escola para aquelas que, sem esta nova medida, estariam fora dela;

2. uniformizar o sistema de educação básica no país, em que coexistem escolas que oferecem ensino com duração de 8 e 9 anos;

3. equiparar o sistema educacional brasileiro ao de outros países do Mercosul;

4. equiparar as oportunidades educacionais entre crianças pobres e as mais favorecidas;

5. oportunizar um salto na qualidade da educação, incluindo a diminuição de vulnerabilidade das crianças a situações de risco, ao aumentar o tempo de permanência na escola e o sucesso no aprendizado;

6. assegurar que, ingressando mais cedo no sistema de ensino, as crianças prossigam por mais tempo em seus estudos, alcançando maior nível de escolaridade;

7. contribuir para mudanças na estrutura e na cultura escolar.

Embora as determinações federais indicassem que o novo Ensino Fundamental poderia ser implantado até o ano de 2010, a Secretaria de Educação do município de que fazem parte as escolas estudadas nesta pesquisa optou por fazê-lo já em 2006.
Com os objetivos de compreender os impactos desta mudança na vida de seus principais destinatários (os alunos, suas professoras, suas escolas e seus pais) e conhecer como foi estruturada a vida acadêmica em 5 Escolas Municipais de Ensino Fundamental, realizamos, durante o ano de 2006, uma pesquisa de campo junto a 8 turmas de primeiros anos. A pesquisa foi desenvolvida focalizando dois eixos: como se deu o processo de ingresso dos alunos menores nas suas novas escolas e quais foram as práticas educacionais mais típicas encetadas nestes espaços educacionais, com especial destaque para análises sobre as condições oferecidas para a atividade lúdica.

O estudo destes dois temas não resultou de mero interesse pessoal. Tanto do ponto de vista teórico (considerando, especialmente, o que vem sendo produzido pela Psicologia), quanto do que sinalizam os documentos do Ministério da Educação, o processo de adaptação escolar e a garantia do direito de brincar são tidos como elementos bastante importantes para a construção de uma escolarização de qualidade, que contribua, de fato, para o desenvolvimento integral dos alunos. Os resultados obtidos pelo desenvolvimento da pesquisa permitiram evidenciar que as escolas tiveram grandes dificuldades para enfrentar os desafios que lhes foram apresentados, em ambos os temas. Entretanto, sem dúvida, foi em relação ao segundo (a garantia do direito de brincar e a organização das práticas pedagógicas) que estas dificuldades apresentaram-se de forma mais aguda. É disto que trataremos a seguir, abordando, primeiramente, o que se almejava que as escolas e suas professoras fizessem e o que de fato ocorreu no ano de implantação do Ensino Fundamental nas turmas pesquisadas.

\section{A atividade lúdica nas práticas educacionais no Ensino Fundamental de 9 anos: o que dizem os documentos e contribuições da Psicologia}

A leitura dos documentos oficiais em que se propõe o novo EnsinoFundamental permite identificaro reconhecimento de que sua implantação/implementação não deve limitar-se a atos burocráticos de matrículas de crianças mais novas, mas sim que exigirá grandes esforços para garantir:

1. a necessária construção de um novo currículo, e

2. a presença privilegiada da atividade lúdica neste novo currículo.

São inúmeras as citações que poderíamos fazer dos documentos, que afirmam estas duas ideias. De nosso ponto de vista, os excertos a seguir são suficientemente ilustrativos:

Partindo do princípio de que o brincar é da natureza de ser criança, não poderíamos deixar de assegurar um espaço privilegiado para o diálogo sobre tal temática [procurando entender] o brincar como um modo de ser e estar no mundo; o brincar como uma das prioridades de estudo nos espaços de debates pedagógicos, nos programas de formação continuada, nos tempos de planejamento; o brincar como uma expressão legítima e única da infância; o lúdico como um dos princípios para a prática pedagógica; a brincadeira nos tempos e espaços da escola e das salas de aula; a brincadeira como 
possibilidade para conhecer mais as crianças e as infâncias que constituem os anos/séries iniciais do ensino fundamental de nove anos. (MEC, 2006b, pp. 11-12).

Com base em pesquisas e experiências práticas, construiu-se uma representação envolvendo algumas das características das crianças de 6 anos que as distinguem de outras faixas etárias, sobretudo pela imaginação, a curiosidade, o movimento e o desejo de aprender aliados à sua forma privilegiada de conhecer o mundo por meio do brincar [...] Esse desenvolvimento possibilita a ela participar de jogos que envolvem regras e se apropriar de conhecimentos, valores e práticas sociais construídos na cultura. (MEC, 2004b, p. 19, grifo nosso).

Nessa idade, em contato com diferentes formas de representação e sendo desafiada a delas fazer uso, a criança vai descobrindo e, progressivamente aprendendo a usar as múltiplas linguagens: gestual, corporal, plástica, oral, escrita, musical e, sobretudo aquela que lhe é mais peculiar e específica, a linguagem do faz-de-conta, ou seja, do brincar. (MEC, 2004b, p. 20, grifo nosso).

A partir de afirmações deste tipo, o governo deixa clara a necessidade de que "as estratégias pedagógicas" evitem "a monotonia, o exagero de atividades 'acadêmicas' ou de disciplinamento estéril” (MEC, 2004b, p. 16).

Podemos assegurar que estas recomendações encontram substancial fundamentação no que tem sido estudado e pesquisado sobre o brincar nas produções acadêmicas e científicas.

A atividade lúdica é considerada como uma das atividades fundamentais para o desenvolvimento infantil por teóricos de inegável importância para a Psicologia, dentre os quais nos concentraremos nas formulações feitas na abordagem Histórico-cultural, trazendo, especialmente, as colaborações de L.S.Vygotsky, A. N. Leontiev e D. B. Elkonin. Esta escolha justifica-se não só por ser a matriz teórica que fundamenta nosso trabalho mas, também, por ser indicada, sistematicamente, como importante referência dos documentos produzidos como orientadores para as ações pedagógicas no sistema educacional brasileiro (conforme pode ser verificado em MEC, 1998a, 1998b, 2006b) ${ }^{1}$.

Vygotsky, Leontiev e Elkonin, com o objetivo de explicar as razões da constituição e do desenvolvimento do psiquismo humano, mostram que isto ocorre como resultado das

Relações [...] determinadas pelas condições históricas concretas, sociais, nas quais o homem se desenvolve e também pela maneira como a sua vida se forma nessas condições e como ele se apropria das objetivações já produzidas e transmitidas por intermédio da educação (Facci, 2004, p. 79).

Para estes autores, a atividade lúdica constitui uma destas objetivações e sua apropriação por parte das crianças, através da educação, provoca transformações radicais nas possibilidades de desenvolvimento psicológico humano.

1 É certo que os modos como a teoria Histórico-cultural é apropriada por estes documentos oficiais têm sido objeto de críticas, tais como as apresentadas em Faria e Palhares (1999), Arce (2006) e Rocha (2007). Entretanto, escapa aos objetivos do presente texto abordá-las.
Importa, desde já, esclarecer que - da perspectiva da teoria Histórico-cultural - nem toda modalidade de atividade lúdica tem o mesmo impacto sobre o desenvolvimento infantil. Considerando a forma clássica de categorizar as brincadeiras, proposta pelo sistema ESAR (Garon, 1992), devemos nos lembrar que os jogos podem ser subdivididos em jogos de exercício (mais típicos da fase inicial de desenvolvimento, até 2 anos de idade), jogos simbólicos ou jogos de faz de conta (que, na nossa cultura, as crianças tendem a começar a realizar a partir de 2 anos de idade, aproximadamente), jogos de acoplagem (jogos de construção) e jogos de regras (mais comuns a partir de 4 ou 5 anos de idade).

Para Vygotsky (1994), é o jogo de faz de conta que se constitui em instância com intenso potencial para a constituição de zonas de desenvolvimento proximal. Ao definir desta maneira o "faz de conta", este autor destaca que, através deste tipo de brincadeira, desenvolvem- se os processos psicológicos mais importantes no processo de humanização do homem, com especial ênfase para a independência do campo perceptual imediato, a capacidade de operar no plano simbólico, a apropriação de formas culturais de relações e ações sobre o mundo, a linguagem e a imaginação.

Este modo de compreender o faz de conta é igualmente compartilhado por Leontiev (1978, 1988), que nomeia esta modalidade de brincadeira como atividade principal da criança. Por atividade principal, o autor entende aquela em torno da qual se organizam as mais poderosas mudanças psicológicas ao longo da vida de cada sujeito.

Colaborador próximo de Vygotsky, Elkonin (1998) acrescenta contribuições importantes para a compreensão da constituição e desenvolvimento do brincar, especialmente por trazer estudos antropológicos que mostram a historicidade do "faz de conta" e por fazer exames minuciosos sobre a importância da participação dos adultos/mediadores mais experientes nesta atividade. Elkonin (1998) argumenta que, para as crianças brincarem e para desenvolverem suas capacidades lúdicas, é necessário que se disponibilize a elas muito mais do que, meramente, tempo e espaço em sua agenda de atividades diárias. Aborda, de modo especial, as teses de que (i) o tipo de material que se oferece às crianças provoca diferenças fundamentais em seus modos de brincar e que (ii) a participação de educadores é de inestimável importância para o surgimento e desenvolvimento da capacidade de brincar das crianças. Elkonin (1998) está, portanto, interessado em instrumentalizar o professor em sua prática, salientando a necessidade de sua participação nas brincadeiras, com objetivo de desenvolvê-las. Para o autor, a "impressão de espontaneidade no desenvolvimento do jogo de papéis nas crianças surge como consequência de que os adultos não se dão conta da direção que eles, de uma forma natural, realizam" (Elkonin, 1998, p. 178). Aponta, como fundamentos básicos para o trabalho dos professores, os conceitos de zona de desenvolvimento proximal (Vygotsky, 1994) e de mediação pedagógica (Vigotski, 1989).

A partir dos princípios elaborados por estes teóricos, vários trabalhos vêm sendo produzidos com os objetivos de aprofundar e fazer avançar reflexões sobre as contribuições 
da atividade lúdica para o desenvolvimento psicológico das crianças e/ou a importância de investimentos em relação ao brincar nas instituições educacionais de modo a que cumpra seu papel de instituição promotora de desenvolvimento (dentre os quais podemos destacar Alves \& Gnoato, 2003; Carvalho \& Pedrosa, 2002; Góes, 2001; Góes \& Lopes, 2004; Pedroza, 2005; Pontes \& Magalhães, 2003; Robles \& Gil, 2005; Rocha, 2005; Silva, Guimarães, Vieira, Franck, \& Hippert, 2005).

Desta forma, as preocupações expressas nos documentos ganham sustentação e relevância quando são consideradas à luz do que tem sido produzido na abordagem Histórico-cultural sobre a infância, o desenvolvimento infantil, as brincadeiras e as responsabilidades das instituições educacionais em relação a garantir que a prática de atividades lúdicas receba especial destaque nos planejamentos pedagógicos e nos currículos escolares.

O desenvolvimento da pesquisa aqui referida, entretanto, desvelou uma realidade bem diferente do que foi prescrito como ideal para o cotidiano escolar das crianças de 6 anos. Indicaremos, a seguir, a metodologia usada e, posteriormente, os modos como se organizaram as práticas educacionais, destacando o lugar ocupado nelas pelas brincadeiras infantis.

\section{Metodologia}

A metodologia usada para o desenvolvimento do trabalho de campo compôs-se de: observações participantes no cotidiano escolar, entrevistas (com as professoras das turmas pesquisadas, com os seus alunos de 6 anos, com as mães/pais/responsáveis destes alunos) e questionários (respondidos por orientadoras pedagógicas das pré-escolas frequentadas por uma parte das crianças em 2005) ${ }^{2}$. Neste artigo, focalizaremos o que foi registrado e analisado a partir das entrevistas com as professoras e das observações participantes realizadas junto às 8 turmas de primeiro ano. Quando pertinente, serão também trazidas informações obtidas a partir das entrevistas com mães, pais ou responsáveis e dos questionários respondidos pelas coordenadoras das pré-escolas frequentadas por algumas crianças em 2005. Por esta razão, estes procedimentos estão detalhados a seguir.

As observações foram realizadas acompanhando toda a jornada de trabalho das 8 turmas de primeiros anos das 5 escolas, numa frequência de uma vez por semana. Trata-se de escolas municipais, localizadas numa mesma região de uma cidade do interior do estado de São Paulo. Estas escolas atendem, predominantemente, a crianças de classes populares, residentes em bairros próximos a elas.

20 projeto foi aprovado pelo Comitê de Ética em Pesquisa com Seres Humanos e todos os participantes assinaram Termo de Consentimento Livre e Esclarecido. O desenvolvimento do trabalho de campo contou com a colaboração dos alunos Cássia de Souza, Érika Tiemi Tsujimoto, Leandro Gaspareti Alves, Maria Clara Z. Viana, Mariana S. Lorensini, Mayara C. Ferreira, Rafael Marum e Talita Giacomini, graduandos da Faculdade de Psicologia da Puc-Campinas.
As turmas acompanhadas tinham, em média, 27 alunos. A maioria deles $(72,1 \%)$ havia frequentado instituição de educação infantil antes da experiência escolar no Ensino Fundamental. Desta porcentagem, 44,6\% frequentaram equipamentos públicos (creches ou pré-escolas municipais), $17,2 \%$ estiveram matriculadas em pré-escolas particulares e $10,3 \%$ frequentaram instituições não-governamentais. Para $27,9 \%$ das crianças, o ingresso no primeiro ano do Ensino Fundamental representou sua primeira experiência escolar. As observações foram registradas em diários de campo e posteriormente digitadas.

As entrevistas realizadas com as 8 professoras ocorreram em dois momentos: no início do segundo semestre e ao final do ano letivo. Estas entrevistas foram individuais, realizadas na própria escola, com exceção de duas delas, que foram feitas na residência das docentes, por sua solicitação. Durantes as entrevistas, as professoras puderam explicitar suas concepções sobre o Ensino Fundamental de 9 anos, sobre a forma como foi implantado, suas expectativas com relação ao trabalho pedagógico que deveriam/gostariam/poderiam desenvolver (sobretudo em relação à inclusão das brincadeiras), as condições materiais disponíveis nas escolas para isso e sobre como os seus alunos vivenciavam o cotidiano escolar. A idade média das professoras era de 39 anos (variando entre 30 e 55 anos). Todas elas eram formadas em Pedagogia, sendo seis, em universidades públicas, uma, em universidade particular e uma professora graduou-se em uma faculdade particular. Duas delas fizeram especialização em Psicopedagogia; as outras seis não têm pós-graduação (lato sensu ou stricto sensu). Todas as professoras tiveram experiências anteriores como professoras de Educação Infantil (em média, durante 6 anos) e todas assumiram a docência no Primeiro Ano do Ensino Fundamental em 2006 por opção própria. Seis professoras dobravam o turno de trabalho em 2006: uma delas trabalhava com alunos de 5 anos, em uma escola de Educação Infantil particular renomada na cidade, três na Educação de Jovens e Adultos (EJA), uma com turma de 6 anos de escola pública de um município vizinho e uma professora trabalhava com alunos de 8 anos, numa escola administrada por uma fundação.

As entrevistas com os pais/mães ou responsáveis foram realizadas nas próprias escolas, com horário agendado pelas professoras. O número de participantes variou (de $1 \mathrm{a}$ 4) a cada encontro. Em função da diferença do número de participantes, a duração das entrevistas foi também bastante variada. Entretanto, quase nunca foram rápidas, durando $1 \mathrm{~h}$ e 30, em média. No total, participaram 58 familiares destes alunos (52 mães, 4 pais e 2 avós). Nestes encontros, foi possível ter acesso às posições destes familiares em relação ao novo Ensino Fundamental, às formas concretas de trabalho pedagógico que vinha sendo realizado pelas professoras das turmas de suas crianças e a informações sobre como as crianças reagiram/estavam reagindo à sua nova vida escolar.

Todas as entrevistas foram desenvolvidas de forma semiestruturada, a partir de um roteiro (específico para cada 
Tabela 1. Distribuição dos episódios de brincadeiras pelas modalidades do sistema ESAR

\begin{tabular}{|l|c|c|c|c|c|}
\hline & $\mathrm{E}$ & $\mathrm{S}$ & $\mathrm{A}$ & $\mathrm{R}$ & TOTAL \\
\hline $\begin{array}{l}\text { Total de episódios lúdicos } \\
\text { realizados pelas crianças/ } \\
\text { modalidade }\end{array}$ & 152 & 63 & 9 & 51 & 275 \\
\hline $\begin{array}{l}\text { Porcentagem de episódios/ } \\
\text { modalidade }\end{array}$ & 55,30 & 22,9 & 3,30 & 18,50 & 100 \\
\hline
\end{tabular}

Fonte: Elaboração dos autores

uma das categorias de protagonistas). Foram gravadas em áudio e, posteriormente, foram transcritas na íntegra para análises.

Os questionários foram encaminhados a 10 coordenadoras pedagógicas das instituições de Educação Infantil frequentadas por parte das crianças no ano de 2005. Compunha-se de 9 perguntas abertas abordando as condições em que foram informadas sobre as mudanças no sistema educacional brasileiro, suas posições em relação a elas, formas utilizadas (ou não) para preparo e orientação dos alunos e de suas famílias para o novo Ensino Fundamental e as reações que puderam observar nestes interlocutores.

A partir destes procedimentos, foi possível identificar os modos como estas instituições educacionais organizaramse para responder às demandas expressas nos documentos oficiais, propostos como guias/referenciais orientadores para o trabalho pedagógico.

\section{Resultados e discussão}

Embora a pesquisa filie-se, predominantemente, à abordagem qualitativa, neste artigo serão apresentadas também algumas análises quantitativas, por considerá-las importantes para descrever com mais clareza o cotidiano escolar. Para as análises quantitativas, utilizamos a categorização de atividade lúdica proposta pelo sistema ESAR (Garon,1992). As análises qualitativas foram feitas sobre as enunciações dos participantes a partir dos conceitos de tema e intertextualidade (Maingueneau, 1997, 2001).

O trabalho analítico sobre as entrevistas com as professoras indicam que, quando solicitamos a elas que avaliassem se e como foi possível garantir a seus alunos oportunidades e investimentos em brincadeiras, às palavras "lúdico", "atividade lúdica", "brincar", "brincadeiras" e "jogos de faz de conta", as docentes associaram os seguintes termos e expressões: "pouco", "muito pouco", "espremido", "ficou sem", "não tem", "raríssimo", "faltou", "não tem espaço", "o espaço é inadequado", "queria ter visto mais", "é mais de correr", "eles não brincam", "poderia ter explorado mais", "não brinquei tanto quanto gostaria de ter brincado", "fiz pouco", "eu errei". Diz uma das professoras entrevistadas
Jane 3 : Ovo choco eu fiz uma vez só. Fiz pouco. A gente fazia no final da aula, quando terminava a atividade. Mas era bem aquela coisa: sobrou tempo, vamos lá. Eu me apeguei mais em sala de aula. Eu errei. Se fosse um pré, quando eu era professora da educação infantil, seria literalmente ao contrário. [Dezembro de 2006].

É certo que este pouco investimento e o frequente deslocamento da atividade lúdica para as sobras de tempo não significaram que as crianças não brincaram durante o período da pesquisa: as observações do cotidiano das turmas de primeiro ano permitiram registrar 275 episódios de brincadeiras. Entretanto, a distribuição destes episódios segundo as modalidades do ESAR (apresentada na tabela a seguir) permite algumas problematizações.

Como podemos observar, houve uma distribuição bastante irregular de frequência dos diferentes tipos de brincadeiras das crianças: a maior parte delas foi "jogos de exercício", a modalidade mais simples/primária em termos de atividade lúdica e mais típica dos dois primeiros anos de vida. Os jogos simbólicos ou de faz de conta aparecem em segunda posição, numa frequência menor do que a metade das vezes em que as crianças brincaram de correr, pular, subir em muretas, escorregar, atirar galhos etc. Além disso, em termos estruturais, estas brincadeiras reduziamse, tipicamente, ao desempenho de ações simples e uso substitutivo de objetos, não tendo sido registrado nenhum episódio em que as crianças desempenhassem papéis ou organizassem suas ações simbólicas em temáticas, o que representa modos mais sofisticados e complexos de brincadeiras. Portanto, pode-se sintetizar que, em relação aos jogos de faz de conta, o que encontramos foram poucas brincadeiras, rápidas ${ }^{4}$ e muito simples.

Em contrapartida, as observações também permitiram identificar que, na maior parte do período em que permaneceram nas escolas, as crianças estiveram envolvidas com atividades instrucionais propostas, incentivadas e

3 Os nomes dos participantes são fictícios.

4 Foram considerados episódios de atividade lúdica todo registro de brincadeiras das quatro modalidades de classificação do Sistema ESAR, independentemente de sua duração. Especialmente os jogos de exercício e os jogos de faz de conta, na maior parte das vezes, duravam apenas alguns segundos. 
Tabela 2. Distribuição das participações das professoras em relação às diferentes modalidades de brincadeiras das crianças.

\begin{tabular}{|l|c|c|c|c|c|}
\hline & E & S & A & R & TOTAL \\
\hline $\begin{array}{l}\text { Total de episódios de atividade } \\
\text { lúdica por modalidade }\end{array}$ & 152 & 63 & 9 & 51 & 275 \\
\hline $\begin{array}{l}\text { Participação das professoras } \\
\text { por modalidade }\end{array}$ & 4 & 0 & 7 & 25 & 36 \\
\hline $\begin{array}{l}\text { Porcentagem de jogos de que } \\
\text { as professoras participaram } \\
\text { por modalidade }\end{array}$ & 11,11 & 0 & 19,44 & 69,45 & 11,28 \\
\hline
\end{tabular}

Fonte: Elaboração dos autores

acompanhadas pelas professoras. Nesta categoria, foram registradas 120 atividades de leitura e escrita e 43 atividades de conhecimentos matemáticos (com duração média de 1 hora cada atividade). Portanto, embora tenham brincado, as crianças estiveram, durante todo o semestre, muito mais ocupadas com atividades de ler, escrever e contar.

Não estamos afirmando, de modo algum, que os jogos de exercício não sejam necessários e importantes para as crianças e, muito menos, que as atividades de alfabetização, de letramento e para o desenvolvimento do raciocínio lógicomatemático não devam ser objeto de frequente e intenso trabalho nas práticas pedagógicas. Ao contrário, em especial no segundo caso, seguramente entendemos que é um dos objetivos principais e responsabilidade da escola fazer circular estes conhecimentos e garantir que as crianças se apropriem deles. Mas, de nosso ponto de vista, as práticas de alfabetização, letramento, aprendizagem matemática e atividade lúdica não são excludentes.

Tendo em perspectiva os aportes dos teóricos que fundamentam este trabalho e, de forma especial, os argumentos de Elkonin (1998) sobre a importância da posição ocupada pelos educadores para provocar novos níveis de desenvolvimento nas brincadeiras das crianças, é importante focalizar os modos de participação das professoras em relação a esta atividade. A partir dos registros das observações, foi possível analisar de quais e de quantas brincadeiras das crianças as professoras participaram. Os resultados encontram-se na tabela 2 , apresentada a seguir.

A leitura da tabela 2 mostra que, em termos totais, as professoras participaram de modo bastante tímido das brincadeiras (envolvendo-se diretamente nelas em apenas $11,28 \%$ dos casos). Novamente aparece irregularidade na distribuição destas participações, já que foi registrado que, em $69,45 \%$ destas ocasiões, a inserção das professoras se deu em relação a jogos de regras. Merece, entretanto, maior destaque o fato de não ter sido registrada nem uma única situação em que as professoras participaram de episódios de faz de conta.

Três linhas de argumentos foram apresentadas por todas as professoras para justificar o que ocorreu: (i) a falta de investimentos dos órgãos públicos para suprir as escolas com recursos materiais necessários, (ii) falta de clareza sobre o que deveriam - de fato - priorizar nas práticas educacionais e (iii) pressões dos pais/responsáveis pelas crianças, no sentido de que investissem mais em atividades do tipo escolar (especialmente em tarefas e produções nos cadernos com conteúdos de alfabetização).

A argumentação mais frequente e aquela sobre a qual as professoras se manifestaram de forma mais contundente referiu-se à extrema precariedade das condições materiais (espaço, equipamentos de parque, jogos e brinquedos) com que tiveram que enfrentar o ano letivo.

As tabelas inseridas a seguir apresentam informações em relação a este tópico, diferenciando a disponibilização de equipamentos/brinquedos para parques e/ou áreas livres (tabela 3) e de jogos e brinquedos para a sala de aula (tabela 4).

Como é possível constatar, de fato as condições oferecidas para a atividade lúdica foram bastante precárias, ao longo de todo o primeiro ano de implantação do Ensino Fundamental de 9 anos nas escolas pesquisadas. Os investimentos realizados pelo poder público foram tímidos, insuficientes e inadequados, como no caso da escola 4, em que os equipamentos de parque foram "herdados" de uma Escola Municipal de Educação Infantil e, ao serem utilizados por crianças de mais idade ${ }^{5}$, rapidamente quebraram. É importante acrescentar que grande parte dos jogos disponíveis em sala de aula foi confeccionado por algumas das professoras com seus próprios recursos financeiros, num esforço pessoal para, ao menos, atenuar a escassez de materiais. Todos estes jogos confeccionados eram jogos de regras e tinham objetivo principal servir como suporte para alfabetização e aprendizagem de conteúdos matemáticos.

As análises da intertextualidade entre os textos do nível micro (discurso das professoras) com o nível macro (discurso oficial) mostram que nenhuma das docentes permaneceu indiferente ou insensível em relação àquilo que puderam disponibilizar para seus alunos. Os resultados

5 Quando instalados, os equipamentos são disputados não só por crianças de 6 anos; as crianças maiores, de 7, 8,9 anos ou mais também desejam utilizá-los e brincar. 
Tabela 3. Distribuição dos equipamentos para parque/áreas abertas, disponíveis nas escolas em 2006.

\begin{tabular}{|c|c|c|c|}
\hline Escola & Equipamentos & $\begin{array}{c}\text { Condições físicas da escola para } \\
\text { instalação }\end{array}$ & Situação ao final de 2006 \\
\hline 1 & não recebeu & não tem espaço & sem equipamentos \\
\hline 2 & casinha e 2 gangorras & necessita de reforma & sem brinquedos \\
\hline 3 & $\begin{array}{c}\text { tirolesa, casinha de Tarzan, } \\
\text { gangorras } \\
\text { e trepa-trepa }\end{array}$ & necessita de reforma & em processo de instalação \\
\hline 4 & $\begin{array}{c}\text { casinha, escorregador, balan- } \\
\text { ço e } 3 \text { gangorras (originalmen- } \\
\text { te destinados a uma escola de } \\
\text { Educação Infantil) }\end{array}$ & boas condições & $\begin{array}{l}\text { instalados e parcialmente quebra- } \\
\text { dos }\end{array}$ \\
\hline 5 & não recebeu & boas condições & sem equipamentos \\
\hline
\end{tabular}

Fonte: Elaboração dos autores

da pesquisa permitiram dar visibilidade ao fato de que o processo de alteração do Ensino Fundamental de 8 para 9 anos foi vivido pelas educadoras com grande angústia, sendo importante destacar que esta palavra foi identificada como um tema (cf. Maingueneau, 1997, 2001) recorrente nas entrevistas realizadas para se referirem ao que sentiram ao longo do ano de 2006.

A seguinte fala de uma das professoras, embora seja singular, sintetiza bastante bem o que foi vivido por todas:

Cláudia: A estrutura da escola pública é uma coisa de louco, né? Nós chegamos, nós não tínhamos nem o nome dos alunos. Não tinha o nome!!! Nós fomos conseguir os nomes passada uma semana de aula. Como que fazia? A gente tinha uma lista não oficial, com os primeiros nomes. Aí, a gente pegava os alunos e ficava lá. Eu comecei a minha turma com 38 alunos. 38!!! Foi desesperador. Desesperador. Porque nós tínhamos uma posição de que nós teríamos no máximo 25 alunos. Aí, você chega com 38, que é quase o dobro!!! É um absurdo!! É um absurdo!! É como uma colega falou: 'Gente! Eu fico imaginando um médico que está lá,

Tabela 4. Distribuição do total de brinquedos disponíveis em sala de aula e/ou em acervos coletivos contabilizados nas 5 escolas, em 2006.

\begin{tabular}{|c|c|c|}
\hline Modalidades & Brinquedos & $\%$ \\
\hline E & 2 & $1,3 \%$ \\
\hline S & 4 & $2,7 \%$ \\
\hline A & 18 & $12,0 \%$ \\
\hline R & 126 & $84,0 \%$ \\
\hline Total & 150 & $100,0 \%$ \\
\hline
\end{tabular}

Fonte: Elaboração dos autores com o cara anestesiado, o corpo aberto em cima da mesa e ele vira e fala assim: o que que a gente vai fazer? É igual a nós: nós estamos com as crianças na sala de aula, precisa fazer alguma coisa, mas a gente não sabe o que fazer'. O que a gente vai fazer? Agora que a gente está discutindo [setembro de 2006]. Então, o corpo está aberto. Lá. E aí? Como que a gente faz?!? Vai operar o coração? Vai desligar o rim? Vai fazer o quê? É como nós. Nós estamos aqui, com a criançada em sala de aula, dentro da sala de aula e a coisa é complicadíssima. Eu acho que faltou um preparo. Faltou se organizar para poder receber esta criançada.

O trecho acima transcrito tem dupla relevância: ao mesmo tempo em que mostra que a angústia das professoras não se referiu apenas aos recursos para as crianças brincarem - sendo extensiva/reativa a vários outros aspectos das condições (in)existentes para seus trabalhos - informa sobre o despreparo das docentes para o trabalho pedagógico que deveriam fazer acontecer.

Todas as educadoras (de Escolas de Ensino Fundamental e Educação Infantil) que participaram da pesquisa afirmaram que experimentaram muita insegurança em relação a como deveriam construir o currículo de seus alunos em função do pouco tempo que tiveram para entenderem e se organizarem frente às demandas da nova proposta. No processo de transição para o novo modo de funcionamento do Ensino Fundamental, segundo elas, prevaleceu a falta de informações sobre como deveria ser a vida das crianças nas escolas. Como consequência, as reuniões que foram realizadas com os pais, mães ou responsáveis e o início do ano escolar foram vividos com grande desconforto por todos os profissionais das escolas, já que tinham, eles próprios, mais dúvidas do que certezas em relação ao futuro acadêmico de seus antigos e novos alunos e sobre o que deveriam fazer com e para eles. Obviamente, esta situação afetou fortemente as práticas pedagógicas das turmas acompanhadas pela pesquisa. 
Éimportante, ainda, acrescentarqueas desinformações sobre o que era para ser feito com seus alunos não foram um problema local das escolas acompanhadas. Gorni (2007), em pesquisa realizada no Paraná com Núcleos Regionais de Ensino, Secretarias Municipais de Educação e escolas públicas da rede municipal e estadual, concluiu que - também neste contexto - muito pouco se sabia a respeito da proposta e aponta para a "evidente precocidade da implantação [do novo Ensino Fundamental] de forma ampla e generalizada, antes que fossem garantidas as condições de preparação das respectivas escolas e professores" (p. 78).

As tensões experimentadas foram intensificadas, entretanto por um outro aspecto: as expectativas dos pais e/ou familiares dos alunos. O desenvolvimento de nosso trabalho nos autoriza a dizer que as professoras tiveram que enfrentar o ano de 2006 premidas entre duas posições antagônicas. Por um lado, pesaram sobre elas pressões dos documentos oficiais propondo/exigindo mudanças na cultura escolar, sintetizadas por afirmações do tipo:

(...) não se trata de transferir para as crianças de 6 anos os conteúdos e atividades da tradicional primeira série, e sim conceber uma nova estrutura de organização dos conteúdos em um Ensino Fundamental de nove anos, considerando o perfil de seus alunos (MEC, 2004b, p. 17).

Por outro lado, também enfrentaram pressões decorrentes das expectativas dos pais, que matricularam seus filhos/suas filhas não na "escola pensada pelo governo", mas na "escola que ensina a ler e a escrever". Assim, no sentido oposto ao dos idealizadores do projeto, os pais esperavam/exigiam exatamente que seus filhos aprendessem conteúdos e atividades da tradicional primeira série do Ensino Fundamental.

Tensões e enfrentamentos deste tipo foram indicados por todas as professoras participantes como um dos aspectos que dificultaram, desde o início do ano escolar, seus investimentos para pensar novos modos de estruturação de suas práticas. As entrevistas realizadas por nós com os pais, mães ou responsáveis confirmaram que, desde o momento da matrícula, estes demonstraram fortes expectativas de que as crianças fossem alfabetizadas e - com exceção de 2 mães - nenhuma expectativa/desejo de que a escola garantisse a elas o direito de brincar. Esta disposição favorável dos pais para as aprendizagens escolares também foi evidenciada por Santos e Vieira (2006), que mostram como a nova proposta de ensino obrigatório foi uma decisão governamental que angariou simpatias da população, sobretudo das famílias imediatamente envolvidas, gerando adesões, expressões de defesa e argumentações favoráveis a esta.

A priorização de práticas, conteúdos e conhecimentos culturalmente mais valorizados (alfabetização e matemática) no dia a dia das crianças e o deslocamento (para segundo, terceiro planos) das brincadeiras simbólicas permitem-nos encerrar o presente artigo levantando algumas questões.

\section{Considerações Finais}

O quadro geral sobre o lugar ocupado pela atividade lúdica - e, de modo especial, pelo faz de conta - é, de nossa perspectiva, preocupante porque pode representar possíveis prejuízos no que se refere ao enriquecimento da imaginação, da capacidade de operar no campo simbólico, de independência do campo perceptual imediato e da apropriação de formas culturais de relações e ações sobre o mundo destas crianças, processos já apontados como especialmente possíveis/importantes de se desenvolverem neste tipo de brincadeira.

Entretanto, convém lembrar que estes resultados referem-se ao ano exato de implantação do projeto e que reformas ou mudanças no sistema educacional devem ser acompanhadas e avaliadas por um período maior de tempo para que se possa identificar de que modo se consolidam (ou não) no interior da cultura escolar. É sabido que, mesmo quando se trata de implantações/implementações de políticas públicas educacionais que obtêm sucesso em seus anos iniciais, este quadro pode mudar nos anos que se seguem à reestruturação educacional, em função da diminuição da difusão e divulgação na mídia, diminuição de investimentos técnico-financeiros etc. Há, em pesquisas realizadas (como, por exemplo, Santos \& Vieira, 2006), registros de que a mobilização que novas políticas provocam nos protagonistas que elas afetam (quer seja uma mobilização de adesão, quer seja de oposição ou resistência) tende a diminuir com o passar do tempo

Éapartirdestas consideraçõesqueaseguinte pergunta deve ser formulada: como tem ocorrido a continuidade de implementação do Ensino Fundamental de 9 anos nestas escolas? Algumas questões mais específicas também são possíveis, tendo em vista os resultados de 2006: a angústia vivida pelas professoras tende a se atenuar pela habituação às condições de trabalho e seus questionamentos em relação à importância da atividade lúdica no contexto educacional tendem a diminuir/desaparecer? Ou, ao contrário, o acúmulo de experiências frente aos novos desafios conduzirão as escolas, suas professoras e o poder público a movimentos construtivos no sentido de efetiva modificação das práticas cotidianas de escolarização das crianças de 6 anos? Os modos de participação das professoras junto aos jogos de faz de conta sofrerão transformações ou se manterá estável o panorama de distanciamento das educadoras em relação a esta modalidade lúdica? A experiência maior e oportunidade de estudo e clarificação dos objetivos do Ensino Fundamental de 9 anos permitirão às professoras e às escolas encontrarem argumentos para explicar aos pais a importância de outras atividades que não só as de alfabetização - e provocar mudanças nos modos como estes avaliam as experiências escolares de seus/suas filhos/filhas, ou os antagonismos entre o discurso oficial e as expectativas dos pais permanecerão intactos? O pouco investimento do poder público registrado em relação às condições de trabalho educacional foi circunstancial ao ano de 2006 e temporário ou permanece, predominantemente, desta forma? 
Ou seja: após o ano inicial de adoção do novo Ensino Fundamental será possível identificar mudanças e avanços nos modos como vem sendo construída a vida escolar das crianças que frequentam as novas turmas de primeiros anos ou os problemas que a pesquisa revelou tenderam a se cronificar e se estabilizaram como forma mais típica e regular de funcionamento das escolas?

As respostas a estas perguntas, seguramente, só serão possíveis com a continuidade do trabalho de campo e com a oportunidade de diálogo com outros trabalhos que venham sendo realizados sobre este tema.

\section{Referências}

Alves, A. M. P., \& Gnoato, G. (2003). O Brincar e a Cultura: jogos e brincadeiras na cidade de Morretes na Década de 60. Psicologia em Estudo, 8(1), 11-117.

Arce, A. (2006). A Brincadeira de Papéis Sociais como Produtora de Alienação no Referencial Curricular Nacional para a Educação Infantil. Em A. Arce \& N. Duarte (Orgs.), Brincadeira de Papéis Sociais na Educação Infantil: as contribuições de Vigotski, Leontiev e Elkonin (pp. 99-116). São Paulo: Xamã.

Ministério da Educação e do Desporto. Secretaria de Educação Fundamental. (1998a). Referencial Curricular para a Educação Infantil (vol.1: Introdução). Brasília: MEC/SEF.

Ministério da Educação e do Desporto. Secretaria de Educação Fundamental. (1998b). Referencial Curricular para a Educação Infantil, (vol.3: Conhecimento de mundo). Brasília: MEC/SEF.

Ministério da Educação e do Desporto. Secretaria de Educação Básica. (2004a). Ampliação do Ensino Fundamental para Nove Anos - Relatório do Programa. Brasília: MEC/SEB.

Ministério da Educação e do Desporto. Secretaria de Educação Básica. (2004b). Ensino Fundamental de Nove Anos - Orientações Gerais. Brasília: MEC/SEB.

Ministério da Educação e do Desporto. Secretaria de Educação Básica. (2006a). Ampliação do Ensino Fundamental para Nove Anos - Terceiro Relatório do Programa. Brasília: MEC/SEB.

Ministério da Educação e do Desporto. Secretaria de Educação Básica. (2006b). Ensino Fundamental de Nove Anos: orientações para a Inclusão da Criança de Seis Anos de Idade. Brasília: MEC/ SEB.

Carvalho, A. M. A., \& Pedrosa, M. I. (2002). Cultura no Brinquedo. Estudos de Psicologia, 7(1), 181-188.

Elkonin, D. B.(1998). Psicologia do Jogo. Martins Fontes: São Paulo.

Facci, M. G. D. (2004). A periodização do desenvolvimento psicológico individual na perspectiva de Leontiev, Elkonin e Vigostski. Cadernos Cedes, 24(62), 64-81.

Faria, A. L. G., \& Palhares, M. S. (Orgs). (1999). Educação Infantil pós-LDB: rumos e desafios. Campinas: Autores Associados- FE/ Unicamp.

Garon, D. (1992). Classificação e Análise de materiais lúdicos - O sistema ESAR. Em A. Friedmann (Org.), O Direito de Brincar: a brinquedoteca (pp. 171-182). São Paulo: Página Aberta.

Góes, M. C. R. de. (2001). O Brincar de crianças surdas: examinando a linguagem no jogo imaginário. Em Anais da 24a Reunião Anual da Anped. Caxambu, MG: Anped.
Góes, M. C. R. de, \& Lopes, P. (2004). A Linguagem no Brincar: repercussões do "faz-de-conta" para o processo de letramento. Em A. C. B. Lodi, K. M. P. Harrison \& S. R. L. Campos (Orgs.), Leitura e Escrita no Contexto da Diversidade (pp. 9-18). Porto Alegre: Mediação.

Gorni, D. A. P. (2007). Ensino Fundamental de nove anos: estamos preparados para implantá-lo?. Ensaio: avaliação de políticas públicas Educacionais, 15(54), 67-80.

Lei $n$. 11.114 , de 16 de maio de 2005. (2005, 16 de maio). Torna obrigatório o início do ensino fundamental aos seis anos de idade. Diário Oficial da União.

Lei n. 11.274, de 06 de fevereiro de 2006. (2006, 06 de fevereiro). Dispõe sobre a duração de nove anos do ensino fundamental, com seu início aos seis anos. Diário Oficial da União.

Leontiev, A. N. (1978). O Desenvolvimento do Psiquismo na Criança. Em A. N. Leontiev, O Desenvolvimento do Psiquismo (pp.285313). Lisboa: Horizonte Universitário.

Leontiev, A. N. (1988). Os Princípios Psicológicos da Brincadeira Pré-escolar. Em L. S. Vigotski, A. R. Luria \& A. N. Leontiev, Linguagem, Desenvolvimento e Aprendizagem (pp. 119-142). São Paulo: Ícone.

Maingueneau, D. (1997). Os Termos-chave da Análise do Discurso. Lisboa: Gradiva.

Maingueneau, D. (2001). Análise de Textos de Comunicação. São Paulo: Cortez.

Pedroza, R. L. S. (2005). Aprendizagem e subjetividade: uma construção a partir do brincar. Revista do Departamento de Psicologia - UFF, 17(2), 61-76.

Pontes, F. A. R., \& Magalhães, C .M. C. (2003). A estrutura da brincadeira e a regulação das relações. Psicologia: Teoria e Pesquisa, 18(2), 213-219.

Robles, H. S. M., \& Gil, M. S. C. A. (2005). O Controle Institucional na Brincadeira entre Crianças com Diferentes Repertórios. Revista Psicologia: reflexão e crítica, 19(2), 19 7-205.

Rocha, M. S. P. M. L. da. (2005). Não Brinco Mais: a (des)construção do brincar na educação infantil. ljuí, RS: Unijuí.

Rocha, M. S. P. M. L da. (2007). O Ensino de Psicologia e a Educação Infantil: a nova política pública para a Educação Infantil e o Ensino Fundamental e suas possíveis repercussões para o desenvolvimento psicológico infantil. ETD - Educação Temática Digital, 8, 266-277.

Santos, L. L. C. P., \& Vieira, L. M. F. (2006). Agora seu filho entra mais cedo na escola: a criança de seis anos no Ensino Fundamental de nove anos em Minas Gerais. Rev. Educação e Sociedade, 27(96), 775-796. Recuperado: 10 jan. 2009. Disponível: http:// www.cedes.unicamp.br.

Silva, L. S., Guimarães, A. B., Vieira, C. E., Franck, L. N. S., \& Hippert, M. I. S. (2005). O Brincar como portador de Significados e Práticas Sociais. Revista do Departamento de psicologia UFF, 17(2), 77-87.

Vigotski, L. S. (1989). A Aprendizagem e o Desenvolvimento Intelectual na Idade Escolar. Em L. S. Vigotski, A. R. Luria \& A. N. Leontiev, Linguagem, Desenvolvimento e Aprendizagem (pp. 103-117). São Paulo: Ícone.

Vygotsky, L. S. (1994). A Formação Social da Mente. São Paulo: Martins Fontes. 
Recebido em: 25/01/2008

Reformulado em: 18/12/2009

Aprovado em: 18/12/2009

\section{Sobre a Autora}

Maria Silvia Pinto de Moura Librandi da Rocha (silrocha@uol.com.br)

Pontifícia Universidade Católica de Campinas

\section{Correspondência}

Maria Silvia Pinto de Moura Librandi da Rocha

Av. Barão de Itapura, 3044

Taquaral - Campinas - São Paulo

CEP: $13073-300$

\section{Agradecimentos}

O trabalho de campo contou com a colaboração dos alunos Cássia de Souza, Érika Tiemi Tsujimoto, Leandro Gaspareti Alves, Maria Clara Z Viana, Mariana S. Lorensini, Mayara C. Ferreira, Rafael Marum e Talita Giacomini, graduandos da Faculdade de Psicologia da Pontifícia Universidade Católica de Campinas. 